\title{
A method for evaluating the performance of a marine piston internal combustion engine used as the main engine on a ship during its voyage in different sailing conditions
}

\author{
Jerzy Girtler, Prof. \\ Gdańsk University of Technology
}

\begin{abstract}

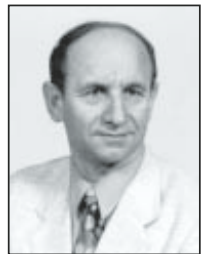

A method is presented for evaluating the performance of piston internal combustion engines used as the main engines on sea-going ships and acting in typical operating conditions. These conditions are described taking into account the performance area of engines of this type. The presented method provides opportunities for calculating the numerical effect of the action using the integral calculus. The above effect is presented as a physical quantity expressed by a number with the metric unit called the joule-second. Proposed is the use of types of integrands (which are functional dependences of the energy converted in these engines on time) which make it possible to use the second fundamental theorem of calculus justifying the use of the Newton-Leibniz formula. The object of the analysis is the process of changes of the energy converted in the internal combustion engines during their operation, described with the aid of a deterministic model of the real process taking into account its sample realisation.
\end{abstract}

Keywords: engine operation; combustion engine performance evaluation; interpretation of energy conversion; Newton-Leibniz formula; model of engine operation

\section{INTRODUCTION}

In the references $[2,3,4,5,8,9,10]$ their authors propose to interpret the operation of an internal combustion engine as the machine energy state which allows the delivered energy to be converted and transmitted to the receivers, such as, for instance, propellers, pumps, compressors, etc. For the operation understood in the above way, a method was proposed for evaluating the operation of piston Diesel engines used in marine industry, which would take into account engine wear $[2,3,6]$. The method based of a well founded assumption that the increasing wear (of both the surface and volumetric nature) of the piston internal combustion engines, like in case of other energy conversion machines, is accompanied by decreasing efficiency of conversion and transmission of the delivered energy $[7,11]$.

The presently proposed method for evaluating the performance of the piston internal combustion engines used as the main engines on the ships (the engines used in the main propulsion system of the ship) takes into account the fact that correct operation of these engines requires securing the delivery of relevant portion of energy to the energy receiver, which is the screw propeller. Securing the energy transmission to the propeller requires from the main engine to operate in such a way that that the ship is able to move at required speed in certain sailing conditions, which are most of all determined by the height and length of the waves, the speed and direction of the wind, the speed and direction of the sea currents, and the depth and width of the water region on which the ship sails. The above operation requires converting relevant portions of energy in working spaces (cylinders) of the main engine, depending on current sailing conditions. This energy is delivered in the fuel and air to the engine combustion chambers during engine operation. The operation of the main engine consists in converting this energy into heat and work and its further transmission to the ship's screw propeller as the energy receiver. In the case of piston internal combustion engines, the chemical energy contained in the fuel-air mixture is firstly converted in the combustion chambers into the thermal energy (heat) of the exhaust gas, and than - into the mechanical energy of the moving piston from the upper top centre (TDC) to the bottom dead centre (BDC). This interpretation of the energy conversion takes into account that the heat is the form of energy conversion from the chemical energy of the fuel-air mixture into the thermal energy, while the work is the form of energy conversion from the thermal energy into the mechanical energy $[3,7]$. Obviously, the energy conversion in the engine is accompanied by changes of the converted energy.

During the engine operation, the energy (E) can be converted at different rates, to respond to the requirements connected with the current task to be done by the engine $[7,11]$. The energy conversion rate is meant here as the amount of energy related to the time unit (energy flux) and denoted as $\dot{\mathrm{E}}=\mathrm{a}$. Generally, the above task can be understood as delivering the energy needed for executing the task in certain operating conditions and certain time. The engine operation, understood as energy delivery in certain time, will take larger and larger values with the increasing time of operation. Therefore the 
engine usability for executing the given task can be evaluated by comparing its possible operation with the required operation, necessary for the execution of the given task. The possible operation is the operation which can be executed by the engine at its current technical state, while the required operation is the operation of the engine which secures the execution of the task in the existing operating conditions. Therefore evaluating the operation of the main engine and its usability for executing the given task requires first formulating the conditions of engine operation and then working out the model (deterministic or stochastic) of the operation of the engine which will take into account the sailing conditions.

\section{CONDITIONS OF THE MAIN ENGINE OPERATION}

The conditions of the main engine operation depend on the conditions in which they work, the latter being defined by the external conditions of ship sailing and tasks undertaken by ship users (the crew). The abovementioned conditions and tasks are the reasons why different portions of energy are converted in different times in the engine working spaces. However, in each case the operation of the main engine is determined by its performance area defined by engine speed characteristics, such as: external characteristics and control characteristics $[7,11]$. If the main engine propeller characteristics, which also belong to the group of speed characteristics, are mapped on the engine speed characteristics, then the operating ranges are determined for the given engine.

Figure 1 shows the theoretical characteristics, while the real characteristics are presented in Fig. 2. The real characteristics differ from their theoretical counterparts, as the average torque $\left(\mathrm{M}_{\mathrm{o}}\right)$ of the piston internal combustion engine is the function of the average effective pressure $\left(\mathrm{p}_{\mathrm{e}}\right)$, the values of which depend not only on the dose of the delivered fuel (the fuel charge) but also on the engine rotational speed (n).

The torque $\left(\mathrm{M}_{\mathrm{o}}\right)$ as the function of the average effective pressure $\left(p_{e}\right)$ is given by the following formula $[6,7,11]$ :

$$
\mathrm{M}_{\mathrm{o}}=\mathrm{c}_{\mathrm{s}} \mathrm{p}_{\mathrm{e}}
$$

where:

$$
p_{e}=f\left(G_{p}, W_{d}, p_{d}, R_{\mu}, T_{d}, L_{o}, \lambda, \eta_{v}, \eta_{i}, \eta_{m}\right)
$$

and:

$\mathrm{c}_{\mathrm{s}}$ - coefficient describing constructional characteristics of the engine

$\mathrm{G}_{\mathrm{p}}$ - fuel charge

$\mathrm{W}_{\mathrm{d}}^{\mathrm{p}}-$ net caloric value of the fuel

$\mathrm{p}_{\mathrm{d}}$ - pressure of the air delivered to engine working spaces

$\mathrm{R}_{\mu}$ - universal (absolute) gas constant $(\mathrm{R} \cdot \mathrm{M})$

$\mathrm{T}_{\mathrm{d}}^{\mu}-$ temperature of the air delivered to the engine working spaces

$\mathrm{L}_{\mathrm{o}}$ - theoretical amount of air required for burning $1 \mathrm{~kg}$ of fuel

$\lambda-$ excess air number

$\eta_{\mathrm{v}}-$ efficiency of engine working space (cylinder) filling

$\eta_{i}-$ indicated efficiency

$\eta_{\mathrm{m}}-$ mechanical efficiency of the engine.

The operation of the main engine is limited in time in the overload area, especially in the case of the torque overload area represented by the area $2-3-4-9-2$ on the theoretical characteristic (Fig. 1) and by the area $9^{*}-3^{*}-4-9-9^{*}$ on the real characteristic (Fig. 2). Moreover, the engine cannot also operate long when it is only overloaded with high rotational speed, see the area 6-7-8-9-6 on the theoretical characteristic and the area
$6-7^{*}-10^{*}-9-6$ on the real characteristic. Obviously, the operation of the engine is even more limited in time when it is overloaded with both the load and the rotational speed, which is represented by the area 4-5-6-9-4 on both the theoretical characteristic (Fig. 1) and the real characteristic (Fig. 2).

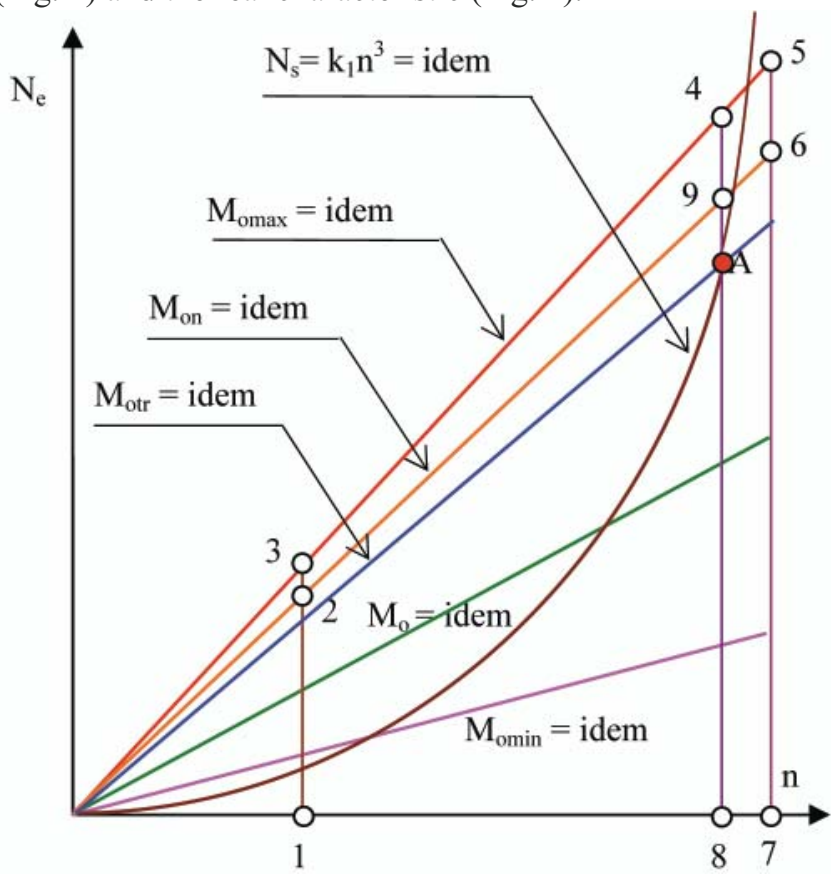

Fig. 1. Theoretical speed characteristics of the piston engine used as the main propulsion (main engine) on a sea-going ship:

- engine performance area (the area of permissible engine loads, the area of so-called stable operation of the engine) $\rightarrow 1-2-9-8-1$, - engine overload area $\rightarrow 2-3-4-5-6-7-8-9-2$

The theoretical characteristics $\mathrm{N}_{\mathrm{e}}=\mathrm{f}(\mathrm{n})$ result from the relation $[6,7,11]$ :

$$
\mathrm{N}_{\mathrm{e}}=\omega \mathrm{M}_{\mathrm{o}}
$$

where:

$\mathrm{N}_{\mathrm{e}}-$ effective power of the engine

$\omega^{\mathrm{e}}-$ rotational speed of the engine crankshaft

$\mathrm{M}_{\mathrm{o}}-$ average torque (turning moment) of the engine.

The real characteristics of the engine (Fig. 2) differ from their theoretical counterparts (Fig. 1) because the torque $M_{0}$ is the function of the average effective pressure $\left(\mathrm{p}_{\mathrm{e}}\right)$, the value of which depends on physical quantities being the functions of the engine rotational speed (n). In general, the relation between the pressure $\mathrm{p}_{\mathrm{e}}$ and the abovementioned quantities is given by the formula (2).

The physical quantities $\lambda, \eta_{v}, \eta_{i}, \eta_{m}$ in formula (2) are the functions of the engine rotational speed (n). Therefore assuming that $\mathrm{W}_{\mathrm{d}}=$ idem, $\mathrm{p}_{\mathrm{d}}=$ idem, $\mathrm{R}_{\mu}=$ idem, $\mathrm{T}_{\mathrm{d}}=$ idem, $\mathrm{L}_{\mathrm{o}}=$ idem, we can write:

$$
\mathrm{p}_{\mathrm{e}}=\mathrm{c}_{\mathrm{p}} \mathrm{n}
$$

where $[6,7]$ :

$$
c_{p}=f\left(G_{p}, W_{d}, p_{d}, T_{d}, R_{\mu}, L_{o}\right)
$$

and:

$\mathrm{G}_{\mathrm{p}}, \mathrm{W}_{\mathrm{d}}, \mathrm{p}_{\mathrm{d}}, \mathrm{T}_{\mathrm{d}}, \mathrm{R}_{\mu}, \mathrm{L}_{\mathrm{o}}$ - physical quantities having the same interpretation as in the description of formula (2).

Since the remaining physical quantities in formula (2) are functions of the engine rotational speed (n), i.e.

$$
\lambda=\mathrm{f}(\mathrm{n}), \eta_{\mathrm{v}}=\mathrm{f}(\mathrm{n}), \eta_{\mathrm{i}}=\mathrm{f}(\mathrm{n}), \eta_{\mathrm{m}}=\mathrm{f}(\mathrm{n})
$$




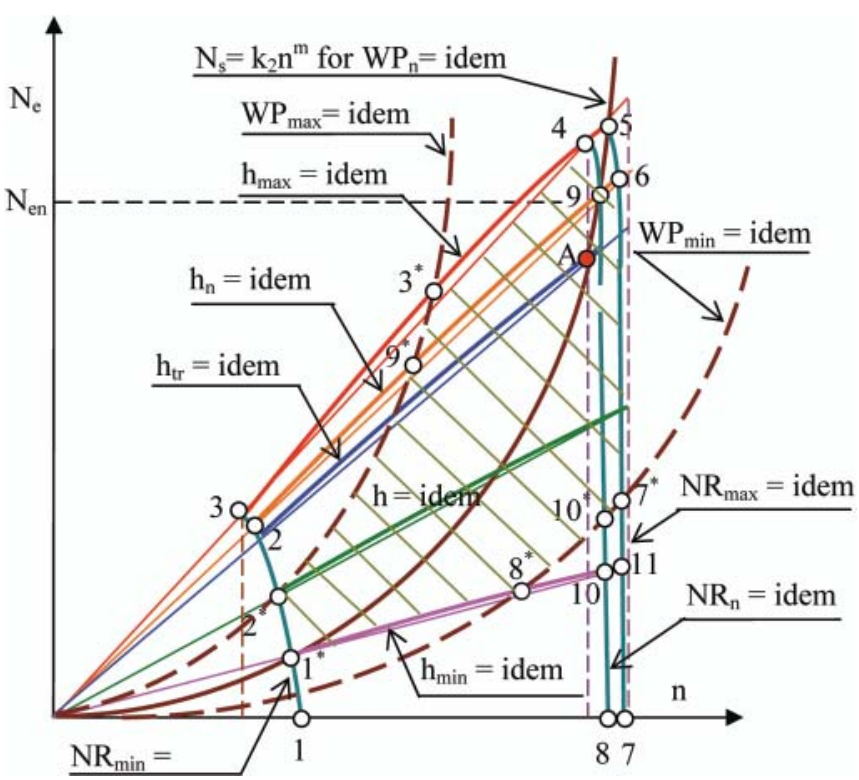

Fig. 2. Speed characteristics of the real piston engine used as the main propulsion (main engine) on a sea-going ship:

- engine performance area (the area of permissible engine loads, the area of so-called stable operation of the engine) $\rightarrow 1^{*}-2^{*}-9^{*}-9-10^{*}-10-8^{*}-1^{*}$;

- engine overload area $\rightarrow 2-3-3^{*}-4-5-6-7^{*}-10^{*}-9-2$;

- area illustrating the range of engine operation (Fig. 2). $1^{*}-2^{*}-9^{*}-3^{*}-4-5-6-7^{*}-10^{*}-8^{*}-1^{*}$

Here: $\boldsymbol{N}_{e}$ - effective power of the engine, $\boldsymbol{N}_{e n}$ - nominal (rated) effective power, $\boldsymbol{n}$ - rotational speed, $\boldsymbol{M}_{0}$ - average torque (turning moment), $\boldsymbol{M}_{\text {omax }}$ - maximal torque, $\boldsymbol{M}_{\text {on }}$ - nominal (rated) torque, $\boldsymbol{M}_{\text {otr }}$ - continuous torque, $\boldsymbol{M}_{\text {omin }}$ - minimal torque, $\boldsymbol{h}_{\max }$ - maximal setting of the injection pump,

$\boldsymbol{h}_{n}$ - nominal (rated) setting of the injection pump, $\boldsymbol{h}_{t r}$ - continuous setting of the injection pump, $\boldsymbol{h}_{\text {min }}$ - minimal setting of the injection pump,

$\boldsymbol{N R}_{\max }$ - maximal setting of the controller, $\boldsymbol{N R}_{n}$ - nominal (rated) setting of the controller, $\boldsymbol{N} \boldsymbol{R}_{\text {in }}$ - minimal setting of the controller,

$\boldsymbol{W P}_{\max }-$ most difficult conditions for ship sailing (largest resistance of motion), $\boldsymbol{W P}$ - nominal conditions for ship sailing, $\boldsymbol{W P}$ - easiest conditions for ship sailing (smallest resistance of motion),

$\boldsymbol{N}_{\boldsymbol{s}}=\boldsymbol{k}_{\boldsymbol{l}} \boldsymbol{n}^{3}$ - theoretical propeller characteristic illustrating the dependence of the power needed by the propeller on the rotational speed (n),

$N_{s}=\boldsymbol{k}_{2} \boldsymbol{n}^{\boldsymbol{m}}$-real propeller characteristic illustrating the dependence of the power needed by the propeller on the rotational speed ( $n), \boldsymbol{k}_{1}$-theoretical power factor, $\boldsymbol{k}_{2}$ - real power factor, $\boldsymbol{m}$-coefficient depending on the shape of the ship hull (for the displacement hulls $m \approx 3,0$ )

then the real performance area (working area) of the engine will be limited by the curves: $\mathrm{h}_{\max }=\mathrm{idem}, \mathrm{NR}_{\max }=\mathrm{idem}, \mathrm{h}_{\min }=\mathrm{idem}$ and $\mathrm{NR}_{\min }=$ idem. However, the engine operation range will be determined by the area smaller than the performance area, as the main engine can only operate in such a way that it secures delivering to the ship propeller the energy which is needed for current task execution. The amount of this energy needed by the screw propeller in certain operating conditions depends on the real propeller characteristic $\mathrm{N}_{\mathrm{s}}=\mathrm{f}\left(\mathrm{k}_{2}, \mathrm{n}\right)$, which is different for different sailing conditions $\mathrm{WP}_{\mathrm{n}}^{\mathrm{s}}=\mathrm{idem}$. In general we can write [11]:

$$
\mathrm{N}_{\mathrm{s}}=\mathrm{k}_{2} \mathrm{n}^{\mathrm{m}}
$$

where:

$\mathrm{k}_{2}, \mathrm{n}, \mathrm{m}$ - physical quantities having the same interpretation as in the description of Fig. 2.

The factor $\mathrm{k}_{2}$ in formula (6) mainly depends on WP (ambient conditions, sailing conditions), which are affected by:

- state of the sea (height, speed and direction of waves),

- speed and direction of sea currents,

- speed and direction of the wind,

- depth and width of the water region on which the ship sails,

- condition of the underwater part of the hull,

- ship's heel and trim.
Moreover this factor depends on the type of ship motion (free motion, towing another ship, etc.), its loading condition, hull dimensions and shape, and the speed of ship motion.

The WP conditions can change within the range from most favourable $\left(\mathrm{WP}_{\min }=\mathrm{idem}\right)$ down to least favourable (WP $=$ idem), which was illustrated in Fig. 2. These conditions determine the operating area for the main engine, which is illustrated by the area: $1^{*}-2^{*}-9^{*}-3^{*}-4-5-6-7^{*}-10^{*}-8^{*}-1^{*}$.

When analysing the operating range of this type of engines, we can consider it obvious [11] that the engine loading conditions change (Fig. 2) from point:

- $1^{*}$ to $2^{*}$ along the control characteristic $\mathrm{NR}_{\min }=\mathrm{idem}$,

- $2^{*}$ to $3^{*}$ along the propeller characteristic $\mathrm{WP}_{\max }=$ idem,

- $3^{*}$ to 4 and 5 along the characteristic of engine external power for the maximal injection pump setting $\mathrm{h}_{\max }=$ idem,

- 5 to 6 and $7^{*}$ along the control characteristic $\mathrm{NR}_{\max }=\mathrm{idem}$,

- $7^{*}$ to $10^{*}$ and $8^{*}$ along the propeller characteristic $\mathrm{WP}_{\min }=$ $=$ idem

- $8^{*}$ to $1^{*}$ along the characteristic of engine external power for the minimal injection pump setting $\mathrm{h}_{\min }=\mathrm{idem}$.

The described range of the main engine operation is shown in Fig. 2 as the hatched area. Within this range the main engine can be loaded with different power $\left(\mathrm{N}_{\mathrm{e}}\right)$ depending on current sailing conditions (WP) and the resultant propeller characteristics changing between $\mathrm{WP}_{\min }$ and $\mathrm{WP}_{\max }$. The power generated by the main engine is always determined by the engine/propeller cooperation point localised at the crossing of the characteristic of engine external power with the propeller characteristic. A sample selection of points of engine/propeller cooperation is shown in Fig. 2, including:

- point A created by crossing of the characteristics $h_{t r}=i d e m$ and $\mathrm{WP}_{\mathrm{n}}=$ idem,

- point 9 created by crossing of the characteristics $h_{n}=$ idem and $\mathrm{WP}_{\mathrm{n}}=$ idem,

- point 5 created by crossing of the characteristics $\mathrm{h}_{\max }=\mathrm{idem}$ and $\mathrm{WP}_{\mathrm{n}}=$ idem

The above cooperation points are created depending on the selected injection pump setting $(\mathrm{h}=\mathrm{idem})$ for one given propeller characteristic (WP $=$ idem). Therefore it may happen that for the given propeller characteristic the main engine can be loaded with power according to the following external power characteristics $[7,11]$ :

- external characteristic of partial power $\mathrm{N}_{\mathrm{ec}}\left(\mathrm{h}_{\mathrm{c}}=\right.$ idem, $\mathrm{c}=1,2, \ldots, \mathrm{N}_{\mathrm{ec}}<\mathrm{N}_{\mathrm{etr}}$,

- external characteristic of continuous operating power $\mathrm{N}_{\text {etr }}$ $\left(\mathrm{h}_{\mathrm{tr}}=\mathrm{idem}\right)$,

- external characteristic of nominal power $\mathrm{N}_{\mathrm{en}}\left(\mathrm{h}_{\mathrm{n}}=\mathrm{idem}\right)$,

- external characteristic of maximal power $\mathrm{N}_{\text {emax }}\left(\mathrm{h}_{\max }=\right.$ = idem).

Sample realisation of changing the main engine power during engine operation is shown in Fig. 3.

The effective power $\mathrm{N}_{\mathrm{e}}$ generated by the main engine (Fig. 2 and Fig. 3) contains the information how fast the effective work $\mathrm{L}_{\mathrm{e}}$ will be done in certain time $\mathrm{t}[7,11]$. That means that the power characterises the engine operation in the aspect of converting the energy into work in the engine working spaces, taking into account different losses, especially thermal losses. However, the engine operation consisting only in energy conversion into work is not possible if earlier the energy has not been converted into heat in the engine working spaces $[2,3,7,11]$. Therefore, when analysing the operation of the main engine we should take into account the energy contained in the air/fuel mixture which, delivered to the engine, is first 


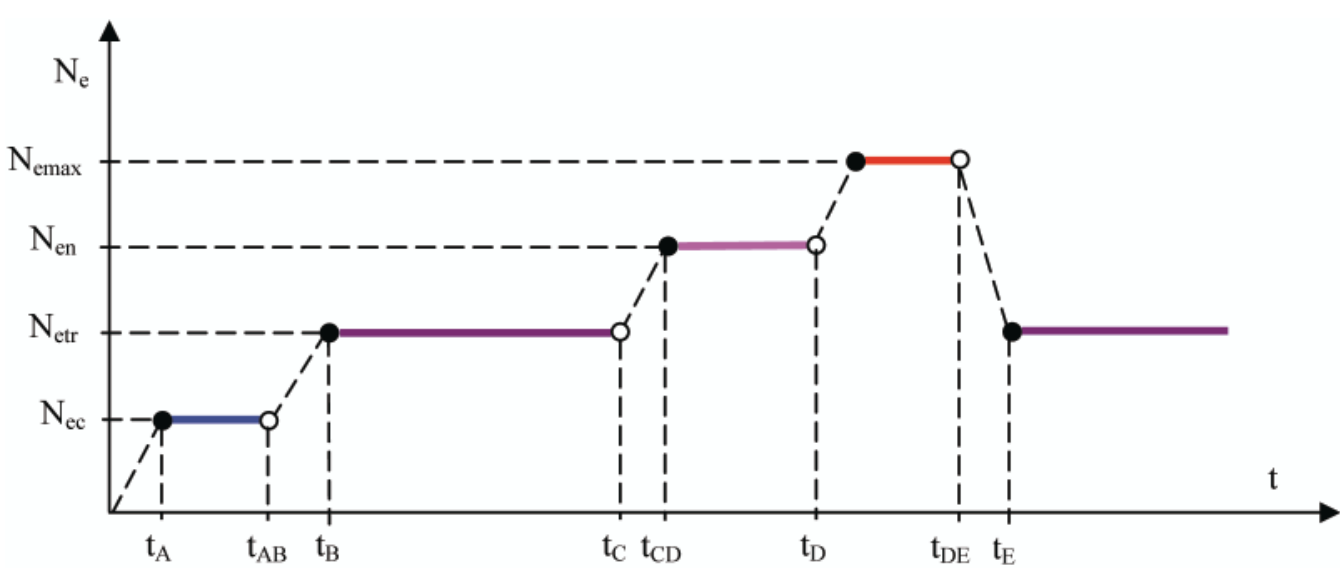

Fig. 3. Sample realisation of the process of main engine load changes during engine operation: $\boldsymbol{N}_{e}-$ effective power, $\boldsymbol{t}$ - time of operation

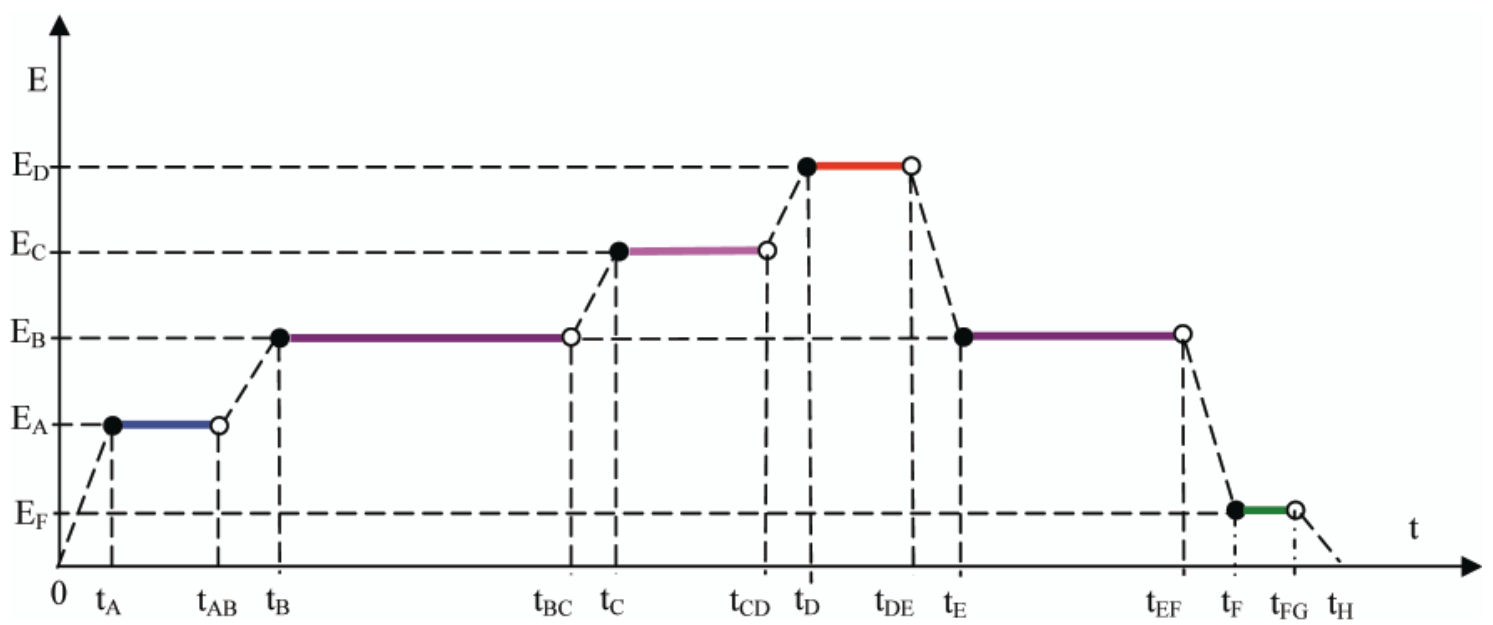

Fig. 4. Realisation of the process of main engine energy changes during engine operation: $\boldsymbol{E}$ - converted energy, $\boldsymbol{t}$ - time of operation

converted to heat $(\mathrm{Q})$ and then to work (L), rather than the engine power output. The analysis should take into account the process of conversion of the energy delivered to the engine. In this process, its particular states are to be the energy states which release the energy $\mathrm{E}_{\mathrm{i}}(\mathrm{i}=\mathrm{A}, \mathrm{B}, \mathrm{C}, \mathrm{D}, \mathrm{F}, \ldots, \mathrm{I})$, to provide opportunities (Fig. 3) for generation particular powers $\mathrm{N}_{\mathrm{ej}}(\mathrm{j}=\mathrm{c}$, tr, $n, \max )$, necessary for correct engine operation and securing the realisation of the operating task.

The above analysis requires working out a deterministic, or stochastic model of the process which secures power changes, like the case shown in Fig. 3, for instance. The discussion presented further in the article bases on the deterministic model of the main engine operation at given time.

\section{DETERMINISTIC MODEL OF MAIN ENGINE OPERATION AND ITS APPLICATION TO PERFORMANCE EVALUATION}

After adopting the deterministic model of the process of main engine operation at given time it is easily to evaluate the engine operation using the integral calculus. Obviously, this evaluation depends on an individual realisation of the above process. Its sample realisation which secures power changes like in the case shown in Fig. 3 is shown in Fig. 4. The model provides opportunities for evaluating the performance of the analysed engine using the integral calculus.

The interpretation of the symbols used in Fig. 4 is the following:

- $\mathrm{t}_{\mathrm{A}}, \mathrm{t}_{\mathrm{B}}, \mathrm{t}_{\mathrm{C}}, \mathrm{t}_{\mathrm{D}}, \mathrm{t}_{\mathrm{F}}$ - operation times, at which the engine energy states appear which make it possible to convert successively the energy $\mathrm{E}_{\mathrm{A}}, \mathrm{E}_{\mathrm{B}}, \mathrm{E}_{\mathrm{C}}, \mathrm{E}_{\mathrm{D}}, \mathrm{E}_{\mathrm{F}}$,
- $t_{E}$, - operation time, at which the engine energy state appears again which makes it possible to convert the energy $\mathrm{E}_{\mathrm{B}}$,

- $\mathrm{E}_{\mathrm{A}}, \mathrm{E}_{\mathrm{B}}, \mathrm{E}_{\mathrm{C}}, \mathrm{E}_{\mathrm{D}}, \mathrm{E}_{\mathrm{F}}$ - energies, which make it possible for the engine to reach the effective powers $\mathrm{N}_{\mathrm{ec}}, \mathrm{N}_{\mathrm{etr}}, \mathrm{N}_{\mathrm{en}} \mathrm{N}_{\text {emax }}$, $\mathrm{N}_{\text {ecmin }}$ (minimal partial power), respectively

- $\mathrm{t}_{\mathrm{AB}}, \mathrm{t}_{\mathrm{BC}}, \mathrm{t}_{\mathrm{CD}}, \mathrm{t}_{\mathrm{DE}}, \mathrm{t}_{\mathrm{FG}}$ - operation times, at which the energy states decay (stop existing) which make it possible to convert successively the energy $\mathrm{E}_{\mathrm{A}}, \mathrm{E}_{\mathrm{B}}, \mathrm{E}_{\mathrm{C}}, \mathrm{E}_{\mathrm{D}}, \mathrm{E}_{\mathrm{F}}$,

- $t_{\mathrm{EF}}$ - operation time, at which the energy state decays again which makes it possible to convert the energy $\mathrm{E}_{\mathrm{B}}$ created at time $t_{E}$,

- $\left\langle 0, \mathrm{t}_{\mathrm{A}}\right\rangle$ - time interval (time) after which the energy $\mathrm{E}_{\mathrm{A}}$ is reached,

- $\left\langle\mathrm{t}_{\mathrm{A}}, \mathrm{t}_{\mathrm{AB}}\right\rangle$ - time interval (time) during which the energy $\mathrm{E}_{\mathrm{A}}$ is converted,

- $\left\langle\mathrm{t}_{\mathrm{AB}}, \mathrm{t}_{\mathrm{B}}\right\rangle$ - time after which the energy $\mathrm{E}_{\mathrm{B}}$ is reached,

- $\left\langle\mathrm{t}_{\mathrm{B}}, \mathrm{t}_{\mathrm{BC}}\right\rangle$ - time during which the energy $\mathrm{E}_{\mathrm{B}}$ is converted,

- $\left\langle\mathrm{t}_{\mathrm{BC}}, \mathrm{t}_{\mathrm{C}}\right\rangle$ - time after which the energy $\mathrm{E}_{\mathrm{C}}$ is reached,

- $\left\langle\mathrm{t}_{\mathrm{C}}, \mathrm{t}_{\mathrm{CD}}\right\rangle$ - time during which the energy $\mathrm{E}_{\mathrm{C}}$ is converted,

- $\left\langle\mathrm{t}_{\mathrm{CD}}, \mathrm{t}_{\mathrm{D}}\right\rangle$ - time after which the energy $\mathrm{E}_{\mathrm{D}}$ is reached,

- $\left\langle\mathrm{t}_{\mathrm{D}}, \mathrm{t}_{\mathrm{DE}}\right\rangle$ - time during which the energy $\mathrm{E}_{\mathrm{D}}$ is converted,

- $\left\langle\mathrm{t}_{\mathrm{DE}}, \mathrm{t}_{\mathrm{E}}\right\rangle$ - time after which the energy $\mathrm{E}_{\mathrm{B}}$ is reached again,

- $\left\langle\mathrm{t}_{\mathrm{E}}, \mathrm{t}_{\mathrm{EF}}\right\rangle$ - time during which the energy $\mathrm{E}_{\mathrm{B}}$ is converted,

- $\left\langle\mathrm{t}_{\mathrm{EF}}, \mathrm{t}_{\mathrm{F}}\right\rangle$ - time after which the energy $\mathrm{E}_{\mathrm{F}}$ is reached,

- $\left\langle\mathrm{t}_{\mathrm{F}}, \mathrm{t}_{\mathrm{FG}}\right\rangle$ - time during which the energy $\mathrm{E}_{\mathrm{F}}$ is converted,

- $\left\langle\mathrm{t}_{\mathrm{FG}}, \mathrm{t}_{\mathrm{H}}\right\rangle$ - time after which the engine is stopped and the energy is not converted any longer (at time $t_{H}$ the energy is $\mathrm{E}_{\mathrm{H}}=0$ ).

Evaluating the performance of the main engine in the form of a number and the metric unit called the joule-second, and presenting this operation in the form of a relevant area in the E-t 
coordinate system, require integrating the energy in particular time intervals and summing up the obtained integrals.

It results from the realisation of the process of main engine energy changes during engine operation, see Fig. 4, that during the time $\mathrm{t}_{\mathrm{A}}$ after starting the engine the energy $\mathrm{E}_{\mathrm{A}}$ is converted. The increase of this energy can be linear (like the case shown in the figure), but can also take a course of the second or third order parabola, depending on the operating strategy of increasing the main engine load.

Evaluating the main engine performance in the time interval between $\left\langle 0, t_{A}\right\rangle$ with the aid of the integral calculus requires finding the antiderivative of the energy $\mathrm{E}(\mathrm{t})$, which is a function of the time of engine operation in this time interval. Therefore we should not only calculate the integrals of the function $\mathrm{E}(\mathrm{t})$, but also decide upon their existence. We can state that the energy functions, both linear and parabolic, have their antiderivatives because they are continuous in the examined time interval $\left\langle 0, \mathrm{t}_{\mathrm{A}}\right\rangle$. The theorem about the existence of these antiderivatives results from the theorem of the existence of the antiderivative, which for the purpose of the engine operation investigations can be formulated in the following way [1]: if the function $\mathrm{E}(\mathrm{t})$ is continuous in the integration interval $\mathrm{T}$, than this function has the antiderivative in this interval. Therefore we can make use of the second fundamental theorem of calculus (the Newton-Leibnitz theorem) and write that the engine performance in the time interval $\left\langle 0, \mathrm{t}_{\mathrm{A}}\right\rangle$ is:

$\mathrm{D}\left(0, \mathrm{t}_{\mathrm{A}}\right)=\mathrm{D}\left(\mathrm{t}_{\mathrm{A}}\right)=\int_{0}^{\mathrm{t}_{\mathrm{A}}} \mathrm{E}(\mathrm{t}) \mathrm{dt}=\left.\mathrm{D}(\mathrm{t})\right|_{0} ^{\mathrm{t}_{\mathrm{A}}}=\mathrm{D}\left(\mathrm{t}_{\mathrm{A}}\right)-\mathrm{D}(0)$

The engine performance in the interval $\left\langle 0, \mathrm{t}_{\mathrm{A}}\right\rangle$ can be calculated from formula (7) assuming one of three earlier mentioned functional relations between the energy and the time, i.e. when:

a) $\mathrm{E}(\mathrm{t})=$ at, and then:

$$
\mathrm{D}\left(0, \mathrm{t}_{\mathrm{A}}\right)=\int_{0}^{\mathrm{t}_{\mathrm{A}}} \mathrm{atdt}=\left.\mathrm{a} \frac{\mathrm{t}^{2}}{2}\right|_{0} ^{\mathrm{t}_{\mathrm{A}}}=\frac{1}{2} \mathrm{at} \mathrm{t}_{\mathrm{A}}^{2}=\frac{1}{2} \mathrm{E}_{\mathrm{A}} \mathrm{t}_{\mathrm{A}}
$$

b) $\mathrm{E}(\mathrm{t})=\dot{\mathrm{a}} \mathrm{t}^{2}$, and then:

$$
\mathrm{D}\left(0, \mathrm{t}_{\mathrm{A}}\right)=\int_{0}^{\mathrm{t}_{\mathrm{A}}} \dot{\mathrm{a}} \mathrm{t}^{2} \mathrm{dt}=\dot{\mathrm{a}} \frac{\mathrm{t}^{3}}{3} \mid{ }_{0}^{\mathrm{t}_{\mathrm{A}}}=\frac{1}{3} \dot{\mathrm{a}} \mathrm{t}_{\mathrm{A}}^{3}=\frac{1}{3} \mathrm{E}_{\mathrm{A}} \mathrm{t}_{\mathrm{A}}
$$

c) $\mathrm{E}(\mathrm{t})=\ddot{a} \mathrm{t}^{3}$, and then:

$$
\mathrm{D}\left(0, \mathrm{t}_{\mathrm{A}}\right)=\int_{0}^{\mathrm{t}_{\mathrm{A}}} \ddot{\mathrm{a}} \mathrm{t}^{3} \mathrm{dt}=\left.\ddot{\mathrm{a}} \frac{\mathrm{t}^{4}}{4}\right|_{0} ^{\mathrm{t}_{\mathrm{A}}}=\frac{1}{4} \ddot{\mathrm{a}} \mathrm{t}_{\mathrm{A}}^{4}=\frac{1}{4} \mathrm{E}_{\mathrm{A}} \mathrm{t}_{\mathrm{A}}
$$

where:

a - engine operation rate, meant as the rate of conversion of the energy E,

$\dot{\mathrm{a}} \quad-$ engine operation rate related to the time unit,

$\ddot{a} \quad-$ derivative of the engine operation rate with respect to time, engine operation acceleration.

In case when the object of concern of the main engine user is such engine operation which is characterised by sole energy conversion into work, the engine operation rate (a) can be interpreted as the power, i.e. the work related to the time at which it was done. This is obvious as the power contains the information how fast the work is, or can be, done. Therefore the power can be interpreted as the rate of work realisation.

In the time interval $\left\langle\mathrm{t}_{\mathrm{A}}, \mathrm{t}_{\mathrm{AB}}\right\rangle$ the energy conversion $\mathrm{E}_{\mathrm{A}}=\mathrm{idem}$ takes place. Therefore in this time interval the engine performance can be evaluated in the following way:

$$
\mathrm{D}\left(\mathrm{t}_{\mathrm{A}}, \mathrm{t}_{\mathrm{AB}}\right)=\int_{\mathrm{t}_{\mathrm{A}}}^{\mathrm{t}_{\mathrm{AB}}} \mathrm{E}_{\mathrm{A}} \mathrm{dt}=\left.\mathrm{E}_{\mathrm{A}} \mathrm{t}\right|_{\mathrm{t}_{\mathrm{A}}} ^{\mathrm{t}_{\mathrm{AB}}}=\mathrm{E}_{\mathrm{A}}\left(\mathrm{t}_{\mathrm{AB}}-\mathrm{t}_{\mathrm{A}}\right)
$$

In the time interval $\left\langle t_{A B}, t_{B}\right\rangle$ the energy converted in the engine working spaces increases from $\mathrm{E}_{\mathrm{A}}$ to $\mathrm{E}_{\mathrm{B}}$. We can assume that the energy increase converted in this interval can be described using similar integrands as for the time interval $\langle 0$, $\left.t_{A}\right\rangle$. But we limit here the engine performance evaluation only to the case of linear energy increase. The area of engine operation in this interval is limited by the following inequalities:

$$
\left.\begin{array}{l}
\mathrm{t}_{\mathrm{AB}} \leq \mathrm{t} \leq \mathrm{t}_{\mathrm{B}} \\
\mathrm{E}_{\mathrm{A}} \leq \mathrm{E}(\mathrm{t}) \leq \mathrm{E}_{\mathrm{A}}+\mathrm{at}
\end{array}\right\}
$$

To make the result of integration more clear, we should change the integration limits taking into account an obvious fact that the energy change takes place in the engine operation time interval $\left\langle 0, \mathrm{t}_{\mathrm{B}}-\mathrm{t}_{\mathrm{AB}}\right\rangle$, which is equal to the interval $\left\langle\mathrm{t}_{\mathrm{AB}}, \mathrm{t}_{\mathrm{B}}\right\rangle$. Then the engine operation area is:

$$
\begin{aligned}
\mathrm{D}\left(\mathrm{t}_{\mathrm{AB}}, \mathrm{t}_{\mathrm{B}}\right) & =\int_{0}^{\mathrm{t}_{\mathrm{B}}-\mathrm{t}_{\mathrm{AB}}}\left(\mathrm{E}_{\mathrm{A}}+\mathrm{at}\right) \mathrm{dt}=\left.\mathrm{E}_{\mathrm{A}} \mathrm{t}\right|_{0} ^{\mathrm{t}_{\mathrm{B}}-\mathrm{t}_{\mathrm{AB}}}+\left.\mathrm{a} \frac{1}{2} \mathrm{t}^{2}\right|_{0} ^{\mathrm{t}_{\mathrm{B}}-\mathrm{t}_{\mathrm{AB}}}= \\
& =\mathrm{E}_{\mathrm{A}}\left(\mathrm{t}_{\mathrm{B}}-\mathrm{t}_{\mathrm{AB}}\right)+\frac{1}{2} \mathrm{a}\left(\mathrm{t}_{\mathrm{B}}-\mathrm{t}_{\mathrm{AB}}\right)^{2}
\end{aligned}
$$

Since:

$$
\mathrm{a}=\frac{\mathrm{E}_{\mathrm{B}}-\mathrm{E}_{\mathrm{AB}}}{\mathrm{t}_{\mathrm{B}}-\mathrm{t}_{\mathrm{AB}}}
$$

where:

$\mathrm{E}_{\mathrm{AB}}=\mathrm{E}_{\mathrm{A}}$

then:

$\mathrm{D}\left(\mathrm{t}_{\mathrm{AB}}, \mathrm{t}_{\mathrm{B}}\right)=\mathrm{E}_{\mathrm{A}}\left(\mathrm{t}_{\mathrm{B}}-\mathrm{t}_{\mathrm{AB}}\right)+\frac{1}{2}\left(\mathrm{E}_{\mathrm{B}}-\mathrm{E}_{\mathrm{A}}\right)\left(\mathrm{t}_{\mathrm{B}}-\mathrm{t}_{\mathrm{AB}}\right)$

where:

a - physical quantity having similar interpretation as in formulas $(8-10)$

In the similar way we can evaluate the engine performance in the remaining time intervals, see (Fig. 4), i.e.:

- in the time interval $\left\langle t_{B}, t_{B C}\right\rangle$ in which the energy $E_{B}=$ idem is converted,

$$
\mathrm{D}\left(\mathrm{t}_{\mathrm{B}}, \mathrm{t}_{\mathrm{BC}}\right)=\int_{\mathrm{t}_{\mathrm{B}}}^{\mathrm{t}_{\mathrm{BC}}} \mathrm{E}_{\mathrm{B}} \mathrm{dt}=\left.\mathrm{E}_{\mathrm{B}} \mathrm{t}\right|_{\mathrm{t}_{\mathrm{B}}} ^{t_{B C}}=\mathrm{E}_{\mathrm{B}}\left(\mathrm{t}_{\mathrm{BC}}-\mathrm{t}_{\mathrm{B}}\right)
$$

- in the time interval $\left\langle\mathrm{t}_{\mathrm{BC}}, \mathrm{t}_{\mathrm{C}}\right\rangle$ in which:

$$
\begin{gathered}
a=\frac{E_{C}-E_{B C}}{t_{C}-t_{B C}}, E_{B C}=E_{B} \\
D\left(t_{B C}, t_{C}\right)=\int_{0}^{t_{C}-t_{B C}}\left(E_{B}+a t\right) d t=E_{B} t_{0}^{\mid t_{C}-t_{B C}}+\left.a \frac{1}{2} t^{2}\right|_{0} ^{t_{C}-t_{B C}}= \\
=E_{B}\left(t_{C}-t_{B C}\right)+\frac{1}{2}\left(E_{C}-E_{B}\right)\left(t_{C}-t_{B C}\right)
\end{gathered}
$$

- in the time interval $\left\langle\mathrm{t}_{\mathrm{C}}, \mathrm{t}_{\mathrm{CD}}\right\rangle$ in which the energy $\mathrm{E}_{\mathrm{C}}=$ idem is converted,

$$
D\left(t_{C}, t_{C D}\right)=\int_{t_{C}}^{t_{C D}} E_{C} d t=\left.E_{C} t\right|_{t_{C}} ^{t_{C D}}=E_{C}\left(t_{C D}-t_{C}\right)
$$


- in the time interval $\left\langle\mathrm{t}_{\mathrm{CD}}, \mathrm{t}_{\mathrm{D}}\right\rangle$ in which:

$$
\begin{gathered}
\mathrm{a}=\frac{\mathrm{E}_{\mathrm{D}}-\mathrm{E}_{\mathrm{CD}}}{\mathrm{t}_{\mathrm{D}}-\mathrm{t}_{\mathrm{CD}}}, \mathrm{E}_{\mathrm{CD}}=\mathrm{E}_{\mathrm{C}} \\
\mathrm{D}\left(\mathrm{t}_{\mathrm{CD}}, \mathrm{t}_{\mathrm{D}}\right)=\int_{0}^{\mathrm{t}_{\mathrm{D}}-\mathrm{t}_{\mathrm{CD}}}\left(\mathrm{E}_{\mathrm{C}}+\mathrm{at}\right) \mathrm{dt}=\left.\mathrm{E}_{\mathrm{C}}\right|_{0} ^{\mathrm{t}_{\mathrm{D}}-\mathrm{t}_{\mathrm{CD}}}+\left.\mathrm{a} \frac{1}{2} \mathrm{t}^{2}\right|_{\mathrm{t}_{\mathrm{D}}-\mathrm{t}_{\mathrm{CD}}}= \\
=\mathrm{E}_{\mathrm{C}}\left(\mathrm{t}_{\mathrm{D}}-\mathrm{t}_{\mathrm{CD}}\right)+\frac{1}{2}\left(\mathrm{E}_{\mathrm{D}}-\mathrm{E}_{\mathrm{C}}\right)\left(\mathrm{t}_{\mathrm{D}}-\mathrm{t}_{\mathrm{CD}}\right)
\end{gathered}
$$

- in the time interval $\left\langle\mathrm{t}_{\mathrm{D}}, \mathrm{t}_{\mathrm{DE}}\right\rangle$ in which the energy $\mathrm{E}_{\mathrm{D}}=$ idem is converted,

$$
\mathrm{D}\left(\mathrm{t}_{\mathrm{D}}, \mathrm{t}_{\mathrm{DE}}\right)=\int_{\mathrm{t}_{\mathrm{D}}}^{\mathrm{t}_{\mathrm{DE}}} \mathrm{E}_{\mathrm{D}} \mathrm{dt}=\left.\mathrm{E}_{\mathrm{D}} \mathrm{t}\right|_{\mathrm{t}_{\mathrm{D}}} ^{t_{\mathrm{t}}}=\mathrm{E}_{\mathrm{D}}\left(\mathrm{t}_{\mathrm{DE}}-\mathrm{t}_{\mathrm{D}}\right)
$$

- in the time interval $\left\langle t_{D E}, t_{E}\right\rangle$ in which:

$$
\begin{gathered}
a=\frac{E_{B}-E_{D E}}{t_{E}-t_{D E}}, E_{D E}=E_{D} \\
D\left(t_{D E}, t_{E}\right)=\int_{0}^{t_{E}-t_{D E}}\left(E_{D}-a t\right) d t=E_{D}\left|a_{D}^{t_{E}-t_{D E}}-a \frac{1}{2} t^{2}\right| \begin{array}{l}
t_{E}-t_{D E} \\
0
\end{array}= \\
=E_{D}\left(t_{E}-t_{D E}\right)-\frac{1}{2}\left(E_{D}-E_{B}\right)\left(t_{E}-t_{D E}\right)
\end{gathered}
$$

since $\mathrm{a}<0$, as $\mathrm{E}_{\mathrm{D}}>\mathrm{E}_{\mathrm{B}}$

- in the time interval $\left\langle t_{E}, t_{E F}\right\rangle-$ i.e. the time in which the energy $\mathrm{E}_{\mathrm{B}}=$ idem is converted,

$$
\mathrm{D}\left(\mathrm{t}_{\mathrm{E}}, \mathrm{t}_{\mathrm{EF}}\right)=\int_{\mathrm{t}_{\mathrm{E}}}^{\mathrm{t}_{\mathrm{EF}}} \mathrm{E}_{\mathrm{B}} \mathrm{dt}=\left.\mathrm{E}_{\mathrm{B}} \mathrm{t}\right|_{\mathrm{t}_{\mathrm{E}}} ^{t_{\mathrm{EF}}}=\mathrm{E}_{\mathrm{B}}\left(\mathrm{t}_{\mathrm{EF}}-\mathrm{t}_{\mathrm{E}}\right)
$$

- in the time interval $\left\langle\mathrm{t}_{\mathrm{EF}}, \mathrm{t}_{\mathrm{F}}\right\rangle$ in which:

$$
\begin{gathered}
\mathrm{a}=\frac{\mathrm{E}_{\mathrm{F}}-\mathrm{E}_{\mathrm{EF}}}{\mathrm{t}_{\mathrm{F}}-\mathrm{t}_{\mathrm{EF}}}, \mathrm{E}_{\mathrm{EF}}=\mathrm{E}_{\mathrm{B}} \\
\mathrm{D}\left(\mathrm{t}_{\mathrm{EF}}, \mathrm{t}_{\mathrm{F}}\right)=\int_{0}^{\mathrm{t}_{\mathrm{F}}-\mathrm{t}_{\mathrm{EF}}}\left(\mathrm{E}_{\mathrm{B}}-\mathrm{at}\right) \mathrm{dt}=\mathrm{E}_{\mathrm{B}}\left|\mathrm{t}_{\mathrm{F}}-\mathrm{t}_{\mathrm{EF}}-\mathrm{a} \frac{1}{2} \mathrm{t}^{2}\right|_{0}^{\mathrm{t}_{\mathrm{F}}-\mathrm{t}_{\mathrm{FF}}}= \\
=\mathrm{E}_{\mathrm{B}}\left(\mathrm{t}_{\mathrm{F}}-\mathrm{t}_{\mathrm{EF}}\right)-\frac{1}{2}\left(\mathrm{E}_{\mathrm{B}}-\mathrm{E}_{\mathrm{F}}\right)\left(\mathrm{t}_{\mathrm{F}}-\mathrm{t}_{\mathrm{EF}}\right)
\end{gathered}
$$

since $\mathrm{a}<0$, as $\mathrm{E}_{\mathrm{B}}>\mathrm{E}_{\mathrm{F}}$

- in the time interval $\left\langle\mathrm{t}_{\mathrm{F}}, \mathrm{t}_{\mathrm{FG}}\right\rangle-$ i.e. the time in which the energy $\mathrm{E}_{\mathrm{F}}=\mathrm{idem}$ is converted,

$$
\mathrm{D}\left(\mathrm{t}_{\mathrm{F}}, \mathrm{t}_{\mathrm{FG}}\right)=\int_{\mathrm{t}_{\mathrm{F}}}^{\mathrm{t}_{\mathrm{FG}}} \mathrm{E}_{\mathrm{F}} \mathrm{dt}=\left.\mathrm{E}_{\mathrm{F}} \mathrm{t}\right|_{\mathrm{t}_{\mathrm{F}}} ^{t_{\mathrm{tg}}}=\mathrm{E}_{\mathrm{F}}\left(\mathrm{t}_{\mathrm{FG}}-\mathrm{t}_{\mathrm{F}}\right)
$$

- in the time interval $\left\langle\mathrm{t}_{\mathrm{FG}}, \mathrm{t}_{\mathrm{H}}\right\rangle$ in which:

$$
\begin{aligned}
& \mathrm{a}=-\frac{\mathrm{E}_{\mathrm{F}}}{\mathrm{t}_{\mathrm{H}}-\mathrm{t}_{\mathrm{FG}}} \\
& \mathrm{D}\left(\mathrm{t}_{\mathrm{FG}}, \mathrm{t}_{\mathrm{H}}\right)=\int_{0}^{\mathrm{t}_{\mathrm{H}}-\mathrm{t}_{\mathrm{FG}}}\left(\mathrm{E}_{\mathrm{F}}-\mathrm{at}\right) \mathrm{dt}=\mathrm{E}_{\mathrm{F}}\left|\mathrm{t}_{\mathrm{H}}-\mathrm{t}_{\mathrm{FG}}-\mathrm{a} \frac{1}{2} \mathrm{t}^{2}\right|_{0}^{\mathrm{t}_{\mathrm{H}}-\mathrm{t}_{\mathrm{FG}}}= \\
& =E_{F}\left(t_{H}-t_{F G}\right)-\frac{1}{2} E_{F}\left(t_{H}-t_{F G}\right)
\end{aligned}
$$

The physical quantity a in equations (8), (13), (16), (18), (20), (22) and (24), meant as the engine operation rate (rate of conversion of the energy E), should be identified both with the rate of energy conversion into work $\left(\mathrm{a}_{\mathrm{L}}\right)$ and into heat $\left(\mathrm{a}_{\mathrm{Q}}\right)$. This results from the fact that in the internal combustion engines the energy conversion into work, done to obtain the required power output, is always accompanied by energy conversion into heat. Therefore evaluating the operation of the engine of this type should not be solely limited to taking into account the power output $\mathrm{N}_{\mathrm{e}}$ as the physical quantity characterising the rate of energy conversion into work. But it does not mean that we cannot, in justified cases, evaluate the performance of internal combustion engines only based on the analysis of the energy conversion into work. In those cases in the above equations the physical quantity a will be the effective power $\left(\mathrm{N}_{\mathrm{e}}\right)$ of an engine of this type $[6,7]$.

The above analysis leads to the conclusion that the main engine performance in the time interval $\left\langle 0, \mathrm{t}_{\mathrm{H}}\right\rangle$, realised in accordance with the energy conversion process whose realisation was shown in Fig. 3 and Fig. 4, can be described in the following way:

$$
\begin{aligned}
& \mathrm{D}\left(0, \mathrm{t}_{\mathrm{H}}\right)=\int_{0}^{\mathrm{t}_{\mathrm{A}}} \mathrm{atdt}+\int_{\mathrm{t}_{\mathrm{A}}}^{\mathrm{t}_{\mathrm{AB}}} \mathrm{E}_{\mathrm{A}} \mathrm{dt}+\int_{0}^{\mathrm{t}_{\mathrm{B}}-\mathrm{t}_{\mathrm{AB}}}\left(\mathrm{E}_{\mathrm{A}}+\mathrm{at}\right) \mathrm{dt}+\int_{\mathrm{t}_{\mathrm{B}}}^{\mathrm{t}_{\mathrm{BC}}} \mathrm{E}_{\mathrm{B}} \mathrm{dt}+ \\
& +\int_{0}^{t_{C}-t_{B C}}\left(E_{B}+a t\right) d t+\int_{t_{C}}^{t_{C D}} E_{C} d t+\int_{0}^{t_{D}-t_{C D}}\left(E_{C}+a t\right) d t+\int_{t_{D}}^{t_{D E}} E_{D} d t+ \\
& +\int_{0}^{t_{E}-t_{D E}}\left(E_{D}-a t\right) d t+\int_{t_{E}}^{t_{E F}} E_{B} d t+\int_{0}^{t_{F}-t_{E F}}\left(E_{B}-a t\right) d t+\int_{t_{F}}^{t_{F G}} E_{F} d t+ \\
& +\int_{0}^{t_{H}-t_{F G}}\left(E_{F}-a t\right) d t=\frac{1}{2} E_{A} t_{A}+E_{A}\left(t_{B}-t_{A B}\right)+ \\
& +\frac{1}{2}\left(E_{B}-E_{A}\right)\left(t_{B}-t_{A B}\right)+E_{B}\left(t_{B C}-t_{B}\right)+E_{B}\left(t_{C}-t_{B C}\right)+ \\
& +\frac{1}{2}\left(E_{C}-E_{B}\right)\left(t_{C}-t_{B C}\right)+E_{C}\left(t_{C D}-t_{C}\right)+E_{C}\left(t_{D}-t_{C D}\right)+ \\
& +\frac{1}{2}\left(E_{D}-E_{C}\right)\left(t_{D}-t_{C D}\right)+E_{D}\left(t_{D E}-t_{D}\right)+E_{D}\left(t_{E}-t_{D E}\right)+ \\
& -\frac{1}{2}\left(E_{D}-E_{B}\right)\left(t_{E}-t_{D E}\right)+E_{B}\left(t_{E F}-t_{E}\right)+E_{B}\left(t_{F}-t_{E F}\right)+ \\
& -\frac{1}{2}\left(\mathrm{E}_{\mathrm{B}}-\mathrm{E}_{\mathrm{F}}\right)\left(\mathrm{t}_{\mathrm{F}}-\mathrm{t}_{\mathrm{EF}}\right)+\mathrm{E}_{\mathrm{F}}\left(\mathrm{t}_{\mathrm{FG}}-\mathrm{t}_{\mathrm{F}}\right)+ \\
& +\mathrm{E}_{\mathrm{F}}\left(\mathrm{t}_{\mathrm{H}}-\mathrm{t}_{\mathrm{FG}}\right)-\frac{1}{2} \mathrm{E}_{\mathrm{F}}\left(\mathrm{t}_{\mathrm{H}}-\mathrm{t}_{\mathrm{FG}}\right)
\end{aligned}
$$

The presented model of the process of energy changes during the time of operation of an arbitrary main engine, and the method for evaluating its performance with the aid of the integral calculus refers to one of numerous possible realisations of the process of load changes in engines of this type. Obviously, during the time of operation of a sea-going ship in various conditions, individual realisations of the energy change process can differ both in the order of appearance of successive engine loads, and their time durations. These loads are the results of changes of the energy $E_{i}(i=A, B, C, D, F, \ldots$, I), Fig. 4. The engine states corresponding to these energies, analysed in the engine operation time, can be interpreted as the processes of changes of the abovementioned energies. The times of appearance of particular states of this process and the 
times of their duration are random variables. Each realisation of the power change process (Fig.3) and its origin - the energy change process (Fig. 4) provides opportunities for analysing the performance of an arbitrary main engine. Moreover, the formulas presented in the article make it possible to express the result of the analysis in the form of a number with the metric unit called the joule-second and in the form of an area bearing the name of the area of operation $[2,3,6]$. The engine operation described in the above way can be called the singular possible operation $\left(\mathrm{D}_{\mathrm{MS}}\right)$. However, for each realisation of this process we can determine the singular required operation $\left(D_{w S}\right)$. In general, the required operation $\left(D_{w}\right)$ can be meant as the operation in which the required energy $E_{W}$ is delivered in the time $t_{w}$ required for task realisation. In the reference to the analysed realisation of the process of main engine energy changes (Fig. 4), the singular required operation $\left(\mathrm{D}_{\mathrm{ws}}\right)$ can be defined as the engine operation which makes it possible to convert the energy $\mathrm{E}_{\mathrm{D}}$ in time not shorter than the time $\mathrm{t}_{\mathrm{W}}=\mathrm{t}_{\mathrm{DE}}-\mathrm{t}_{\mathrm{D}}$, required (needed) for task realisation. If the engine can operate in the above way, then we arrive at the following inequality relation:

$$
\mathrm{D}_{\mathrm{MS}} \geq \mathrm{D}_{\mathrm{wS}}
$$

In this case the engine is capable of doing the task to which it was designed and machined, and therefore can be considered as capable of doing this task, i.e. as the engine at capability state $[3,6]$. In the opposite case, comparing the engine operations $\mathrm{D}_{\mathrm{MS}}$ and $\mathrm{D}_{\mathrm{wS}}$ leads to the inequality:

$$
\mathrm{D}_{\mathrm{MS}}<\mathrm{D}_{\mathrm{WS}}
$$

and the engine is to be considered as incapable of doing the given task, i.e. as the engine at incapability state.

In general we can conclude: if the realisation of a task is only possible when the main engine can be loaded within the entire performance area (Fig. 2), then this engine is capable of doing this task. In that case we can say that the engine is at capability state. The engine at this state can be loaded even according to the external maximal power characteristic $\left(\mathrm{h}_{\max }=\mathrm{idem}\right)$. Obviously, when the engine cannot be loaded according to the external characteristic $h_{\text {max }}=$ idem due to wear of its elements, but according to the characteristics obtained for smaller injection pump setting, for instance the external nominal power characteristic $\left(\mathrm{h}_{\text {nom }}=\right.$ idem), its operational applicability is smaller. Even smaller applicability will characterise the engine which can be only loaded according to the external continuous power characteristic $\left(\mathrm{h}_{\mathrm{tr}}=\mathrm{idem}\right)$, etc.

\section{REMARKS AND CONCLUSIONS}

The article presents the deterministic method for evaluating the performance of a marine piston internal combustion engine used as the main propulsion (main engine) on a ship. The presented method is not limited to the above types of engines, and can also be use for performance evaluation of an arbitrary piston internal combustion engine of both compression-ignition and spark-ignition type.

A separate task is working out a method for evaluating the performance of internal combustion engines in stochastic approach. In this case it should be taken into account that the processes of energy changes realised in time in engine working spaces are stochastic processes. Investigating those processes requires working out their model in the form of a stochastic process which is discrete in states and continuous in time. The discussion presented in the article suggests that the model to be applied here can be the Semi-Markov process, which has the properties of being discrete in states and continuous in time.
The operation of the internal combustion engine is interpreted in the article as delivering the required energy in given time, which can be expressed in the form a physical quantity with the metric unit called the joule-second.

When discussing good and bad points of the energy conversion in internal combustion engines, all aspects of their operation are to be taken in to account and not only their work. The analysis of engine work takes only into account the energy conversion into work, while the energy conversion into heat, which always accompanies the engine work, is neglected.

The proposed method assumes that the energy change can be described by a linear function $(y=a t)$, but it was mentioned that for this purpose also the second or third order parabola can be used (formulas 9 and 10).

It results from the presented discussion that evaluating the engine performance using the integral calculus is possible if the energy, as the integrand, can be expressed in the form of elementary functions. This is because there are no general principles which would make it possible to calculate integrals of arbitrary functions, unlike the situation which takes place in the differential calculus. Therefore the problem here is not only to calculate the integrals to evaluate the engine performance, but also the more general problem of the existence of these integrals.

In practice, sometimes evaluating the engine performance using the Newton-Leibniz formula (7) cannot be done. It refers to the cases when:

- the performance, as the antiderivative of the energy being the integrand, cannot be described using elementary functions,

- the antiderivative expressing the performance cannot be obtained, due to extremely complicated algebraic transformations required and the resultant high expected probability of error appearance,

- the energy changes can only be presented in tabular form, and not as the function of time.

In cases when the Newton-Leibniz formula (7) is not applicable, approximate methods of integration should be used, among which the best known are the trapezoidal rule and the Simpson's rule.

\section{BIBLIOGRAPHY}

1. Delventhal K. M., Kissner A., Kulick M.: Mathematic. Compendium (in Polish) Świat Książki, Bertelsmann Media, 2005. Original title: Groses Buch der Mathematik. Compact Verlag Media, 2001.

2. Girtler J.: Possibility of valuation of operation of marine diesel engines. Journal of POLISH CIMAC, Vol 4, No 1, 2009.

3. Girtler J.: Energy-based aspect of operation of diesel engine. COMBUSTION ENGINES No 2/2009 (137).

4. Girtler J.: Conception of valuation of combustion engine operation. Journal of KONES. Powertrain and Transport. Editorial Office Institute of Aeronautics BK, Warsaw 2008

5. Girtler J.: Energy-based aspect of machine diagnostics. (in Polish) Diagnostyka Nr 1(45)/2008. Wyd. Polskie Towarzystwo Diagnostyki Technicznej, Warsaw 2008.

6. Girtler J.: Work of a compression-ignition engine as the index of its reliability and safety. II International ScientificallyTechnical Conference EXPLO-DIESEL \& GAS TURBINE"01. Conference Procedings. Gdansk-Miedzyzdroje-Copenhagen, 2001.

7. Piotrowski I., Witkowski K.: Operation of marine internal combustion engines. (in Polish) AM, Gdynia 2002.

8. Rosłanowski J.: Identification of ships propulsion engine operation by means of dimensional analysis. Journal of POLISH CIMAC, Vol 4, No 1, 2009. 
9. Rudnicki J.: Loads of ship main diesel . engine in the aspect of practical assessment of its operation. Journal of POLISH CIMACE, Vol. 3, No 1, 2008.

10.Rudnicki J.: On making into account value of operational applied to ship main propulsion engine as an example. Journal of POLISH CIMAC, Vol 4, No 1, 2009.

11. Wojnowski W.: Marine internal combustion engine plants. (in Polish), Part I., Wyd. AMW, Gdynia 1998.
CONTACT WITH THE AUTHOR

Jerzy Girtler, Prof.

Faculty of Ocean Engineering and Ship Technology

Gdansk University of Technology Narutowicza 11/12

80-233 Gdansk, POLAND

e-mail: jgirtl@pg.gda.pl 